\title{
MODELAGEM DE LOTES DE PRODUÇÃO NA EFICIENCIA E PLANEJAMENTO DE SISTEMAS DE OVINOS DE CORTE ${ }^{1}$
}

\author{
Vinícius Pereira Guimarães², Francisco Gilney Silva Bezerra ${ }^{3}$, Fernando Henrique M.A.R. de \\ Albuquerque ${ }^{4}$, Evandro Vasconcelos Holanda Júnior ${ }^{5}$, Marco Aurélio Delmondes Bomfim ${ }^{5}$, Eduardo Luis \\ Oliveira $^{4}$

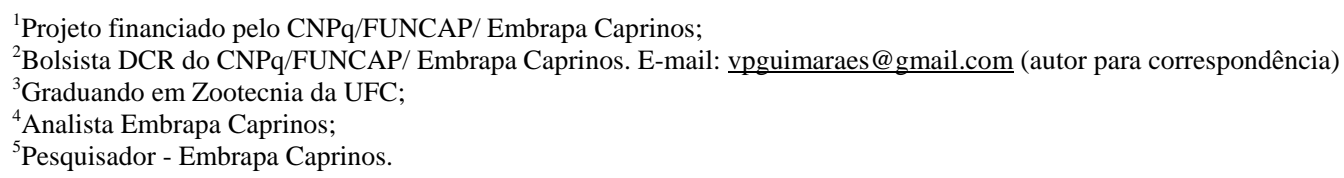

Resumo: No contexto de elevada concorrência e incertezas, o planejamento dos sistemas de produção torna-se, muitas vezes, uma realidade distante e falha, sendo, necessários novos modelos de produção. A modelagem de sistemas de produção apresenta-se, atualmente, como uma possível ferramenta para minimizar essas perdas. Este trabalho objetivou desenvolver um modelo que simulasse os eventos ocorridos em um sistema de produção ovino, em relação ao número de animais e mão-de-obra, para avaliar a utilização de um ou dos lotes de produção. Utilizou-se para tal, o programa Vensim da Ventana Systems ${ }^{\circledR}$. De acordo com a simulação, a demanda de mão-de-obra no sistema com um lote e com dois, respectivamente, foi de 2,53 e 10,05 horas na maior parte do ciclo e 9,28 e 5,08 horas por dia nas estações de monta e nascimento. Respectivamente, o custo com mão-de-obra, por dia, no sistema com 1 e 2 lotes foi de $\mathrm{R} \$ 10,00$ e 20,32 na maior parte do ciclo e de $\mathrm{R} \$ 37,00$ e 40,20 durante as estações,. Ao final da simulação percebeu-se que o número médio de animais ofertados em ambos os sistemas permaneceu em torno de 172 animais. A renda bruta total para o sistema com 1 lote foi de R $\$ 18.173,05$ e R\$18.916,21 para o sistema com 2 lotes. A porcentagem dos custos com mão-de-obra em relação à renda aumentou no sistema com 2 lotes. A simulação mostrou que o sistema 1 traria maior retorno econômico. Todavia, o sistema com 2 lotes de produção possibilita um melhor planejamento, permitindo um maior controle. Conclui-se ainda que o mercado deve estimular, através de bônus, aqueles produtores que optarem pelo sistema de 2 lotes, para que haja uma maior constância na oferta do produto no mercado.

Palavras-chave: modelos, dinâmica de sistemas, mão-de-obra,

\section{MODELING LOTS OF PRODUCTION IN THE PERFORMANCE AND PLANNING OF MEAT SHEEP SYSTEMS}

\begin{abstract}
In a world of high competition and uncertainties, the planning of production systems is often a distant and failure reality, being necessary new models of production. The modeling of production systems shows a interesting tool for minimizing losses in the systems. This study aimed to develop a model to simulate the events that occurred in a system of sheep production, comparing to the number of animals and labor, to evaluate the use of one or two groups of animals in production. For these evaluation was used program Vensim of Ventana Systems ${ }^{\circledR}$. According to the simulation, the demand for labor in the system with 1 group and two groups was, respectively, was 2.53 and 10.05 hours in most parts of the production cycle and 9.28 and 5.08 hours per day at mating season and birth. Respectively, the cost of labor per day in the system with 1 and 2 groups was $\mathrm{R} \$ 10.00$ and 20.32 for most of the cycle and of $\mathrm{R} \$ 37.00$ and $\mathrm{R} \$ 40.20$ during the season. At the end of the simulation was found that the average number of animals offered in both systems remained around 172 animals. The total gross income for the system with 1 group was R $\$ 18173.05$ and R\$18916.21 for the system with 2 groups. The percentage of the labor cost in comparison with the system with 2 groups increased considerably. The simulation showed that the system with 1 group would bring greater economic return. However, the system with 2 groups was a better possible plan, allowing for more control. It is also clear that the market should encourage, through bonuses, those producers who opt for the systems with 2 groups, so there is a more constant supply of the product on the market.
\end{abstract}

Keywords: models, system dynamics, labour. 


\section{Introdução}

Num contexto de elevada concorrência e incertezas, o planejamento dos sistemas de produção torna-se, muitas vezes, uma realidade distante e falha, comprometendo, assim, a competitividade da atividade. Associado a esse problema a falta de estudo de mercado, o desconhecimento das propriedades, por parte dos próprios produtores e dos órgãos responsáveis por elaborar as políticas agrícolas necessárias ao setor e principalmente a estacionalidade na oferta, tem levado ao não desenvolvimento da cadeia produtiva da ovinocultura. O mercado consumidor tem apresentado um aumento no consumo, sendo necessários novos modelos de produção, onde os produtos oriundos da ovinocultura tenham maior constância no mercado durante maior número de meses ao ano. Portanto, planejamento adequado aliado à organização dos produtores e às pesquisas bem orientadas poderão aumentar o período de oferta de animais para abate por maior número de meses do ano (MCT/CNPq/CGAPB, 2001). Desta forma, a busca por ferramentas que venham auxiliar a tomada de decisão, tanto fora quanto dentro da porteira, é imprescindível à produção. A modelagem de sistemas de produção apresenta-se, atualmente, como uma possível ferramenta para minimizar essas perdas, através do entendimento da dinâmica dos eventos do sistema, identificação dos pontos de estrangulamento da produção e orientação da elaboração de projetos para o setor. Por estes motivos, este trabalho teve como objetivo desenvolver um modelo que simulasse os eventos ocorridos em um sistema de produção ovino, referente à relação entre o número de animais e mão-de-obra, na região do Sertão Central do Estado do Ceará, para avaliar a utilização de um ou dos lotes de produção.

\section{Material e Métodos}

Desenvolveu-se o modelo de forma que as variáveis mão-de-obra, número de animais e custo com mão-de-obra estabelecessem, entre sim, uma relação, para avaliar o impacto da mudança no manejo do rebanho, caso o produtor opte por dividi-lo. As demais variáveis como produtos veterinários, alimentação, etc. não foram consideradas nessa análise. O sistema de produção modelado é composto por um rebanho de 90 matrizes ovinas sem padrão racial definido, onde as mesmas são acasaladas com reprodutores das raças Santa Inês, Dorper e Somalis, objetivando cruzamentos industriais. Os indicadores zootécnicos foram calculados com base na escrituração referende a três ciclos de produção. Os dados utilizados nesta simulação são oriundos de coletas junto aos técnicos responsável pela propriedade, além das informações encaminhadas a Embrapa Caprinos. Os animais permanecem em uma área de pastejo rotacionado, onde as crias ficam ao pé até o desmame. Após o desmame são levados para outra área com o mesmo sistema de pastejo. Nesta simulação, trabalhou-se com a área do sistema constante, objetivando otimizar as instalações presentes na propriedade, reduzindo, desta forma, os custos com benfeitorias. Utilizou-se para simulação o programa Vensim, produzido pela Ventana Systems ${ }^{\circledR}$. Os valores referentes ao preço pago pelo kg de carne e a hora de mão-de-obra, são os praticados no município de Sobral, Ceará, onde está localizada a propriedade. Para esse modelo, preconizou-se que todos os animais provenientes dos cruzamentos ao final da fase de cria e acabamento seriam todos vendidos, excetos aquelas fêmeas que são utilizadas para reposição do plantel.

\section{Resultados e Discussão}

De acordo com a simulação, observou-se que ao se optar por trabalhar com somente um lote o produtor terá uma demanda de mão-de-obra diária de aproximadamente 5,03 horas na maior parte do ciclo. Já nos períodos que compreende as estações de monta e nascimento, a demanda passa para 14,95 horas/dia. Em média o custo com mão-de-obra, por dia, foi de $\mathrm{R} \$ 10,06$ na maior parte do ano e de $\mathrm{R} \$ 29,90$ durante as estações de monta e nascimento, o que corresponde a um aumento de 197\%. Estes valores satisfazem ao manejo de um lote de aproximadamente 173 animais (matrizes e crias). A receita média obtida com a venda do lote foi de aproximadamente $\mathrm{R} \$ 6.057,68$. O segundo modelo de produção com as matrizes dividas em dois lotes, criou duas estações de monta em períodos diferentes, causando alteração na demanda de mão-de-obra diária ficando em torno de 19,93 horas nos períodos que ocorrem as estações de monta e nascimento, e 10,03 horas nos demais períodos. O que se percebe é que na maior parte do ano a demanda tende a aumentar em 98\%, todavia nos período que compreende as estações de monta e nascimento há um aumento menos significativo, em torno de 33\%. Isso ocorre devido à mão-de-obra demandada nas práticas de manejo diárias como oferta de água, fornecimento de sal mineral, dentre outros, exigirem um tempo maior de execução. Neste novo sistema, o custo com mão-de-obra é em média de $\mathrm{R} \$ 20,06$ e $\mathrm{R} \$ 39,86$, paras os períodos entre estações e durante as estações, respectivamente. A receita bruta gerada a cada lote é menor quando comparada ao do primeiro sistema, $\mathrm{R} \$ 3.152,70$. Todavia, no primeiro sistema, o período de estacionalidade é maior, podendo gerar uma menor oferta de produto no mercado. No segundo sistema, além de reduzir esse período de estacionalidade de oferta (Figura 1), o produtor terá duas receitas no seu fluxo de caixa. Assim, o mesmo estará recebendo, num intervalo de tempo menor, um valor de $\mathrm{R} \$ 6.305,40$ na venda dos dois lotes. Ao final do período simulado o que se 
percebeu é que o número médio de animais ofertados em ambos os sistemas de produção permaneceu em torno de 249 animais. A renda bruta total para o sistema 1 foi de $\mathrm{R} \$ 18.173,05$ e $\mathrm{R} \$ 18.916,21$ para o sistema 2. A porcentagem dos custos com mão-de-obra em relação à renda total foi de $49 \%$ e $90 \%$ para os sistemas 1 e 2, respectivamente. Isso representa um aumento de 85\% nos custos.
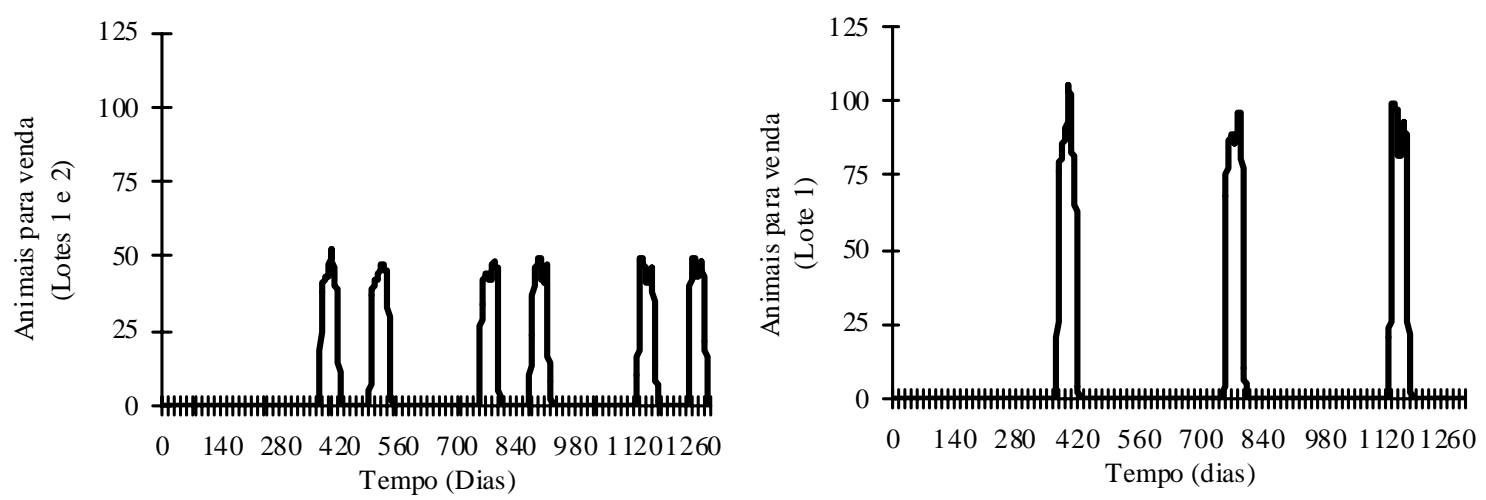

Figura 1 Dinâmica do número de animais e da estacionalidade de oferta de produto de acordo com o sistema de produção.

\section{Conclusões}

A simulação mostrou que para o sistema de produção estudado a opção que traria maior retorno econômico em relação às variáveis estudadas, seria o sistema 1, onde o produtor trabalharia com somente um lote. Todavia, no sistema 2 é possível um melhor planejamento do sistema, devido o produtor ter um número menor de animais por estação, o que lhe permite um maior controle. Conclui-se ainda que o mercado consumidor deve estimular, através de bônus, aqueles produtores que optarem pelo sistema 2, para que haja uma maior oferta do produto no mercado. Caso isso venha ocorrer, o sistema 2 poderá passar a ser mais interessante ao produtor.

\section{Literatura citada}

REUNIÃO TÉCNICA APOIO À CADEIA PRODUTIVA DA OVINOCAPRINOCULTURA BRASILEIRA, 2001, Brasília, DF. Relatório final. Brasília, DF: MCT; CNPq: CGAPB, 2001. 70 p. 